\title{
Twelve recommended social and behavior change indicators for family planning
}

Breakthrough RESEARCH

Follow this and additional works at: https://knowledgecommons.popcouncil.org/departments_sbsr-rh How does access to this work benefit you? Let us know!

\section{Recommended Citation}

Breakthrough RESEARCH. 2020. "Twelve recommended SBC indicators for family planning," Programmatic Research Brief. Washington, DC: Population Council. 


\section{Twelve Recommended SBC Indicators for Family Planning}

This brief describes 12 indicators that align with the ideational model of social and behavior change (SBC) interventions that countries and programs can consider adopting to monitor and evaluate their family planning (FP) programs. The recommended indicators can support countries, donors, and implementing partners to strengthen their SBC measurement and improve program performance.

A growing body of evidence suggests that SBC interventions increase use of modern contraceptives and, ultimately, generate a positive return on investments in FP. ${ }^{1}$ Evidence suggests that SBC interventions can directly increase contraceptive uptake and use through pathways that address intermediate indicators such as attitudes and communication around FP (see figure 1). However, some SBC interventions are more effective than others, and the effectiveness of SBC interventions varies depending on the existing modern contraceptive prevalence rate and intermediate knowledge, attitudes, beliefs, and risk perceptions.

\section{KEY POINTS}

- SBC measurement enables programs to engage in continuous learning and improvement, enables programs to demonstrate how SBC interventions improve desired outcomes, and provides evidence of SBC's effectiveness that can be used to mobilize further investment.

- Countries and programs should consider adopting indicators that align with SBC frameworks such as the ideational model, which describe stages of the innovation-decision process prior to behavior change.

We propose 12 SBC indicators that programs can consider adopting to monitor and evaluate SBC programs.

SBC measurement enables programs to engage in continuous learning and improvement, enables programs to demonstrate how SBC interventions improve desired outcomes, and provides evidence of SBC's effectiveness that can be used to mobilize further investment. Countries and programs should consider adopting indicators that align with SBC frameworks

Figure 1 Ideational Model of SBC Interventions

EXPOSURE TO SBC PROGRAMMING

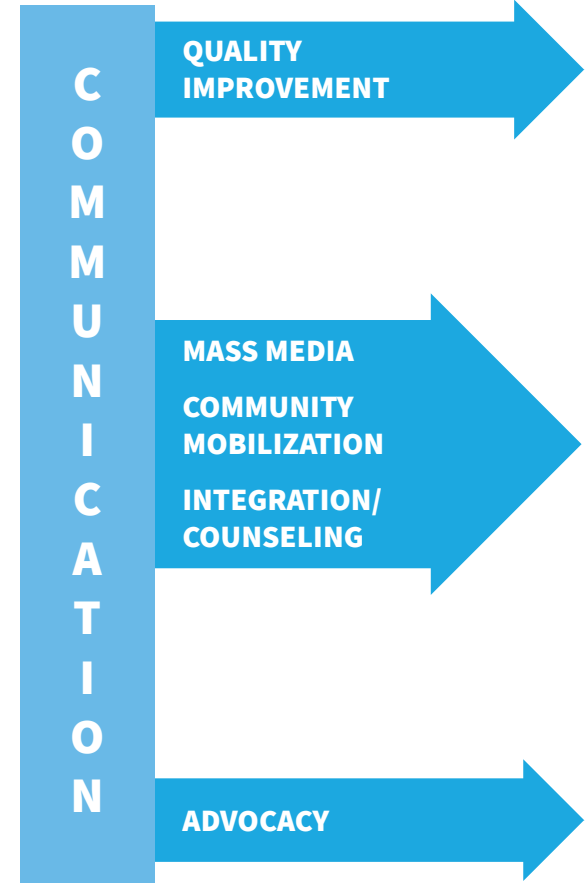

INTERMEDIATE

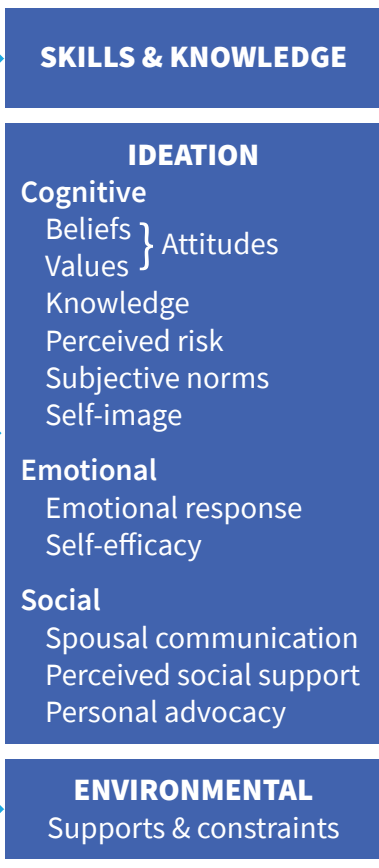

INTENTION AND

\section{BEHAVIORAL OUTCOMES}

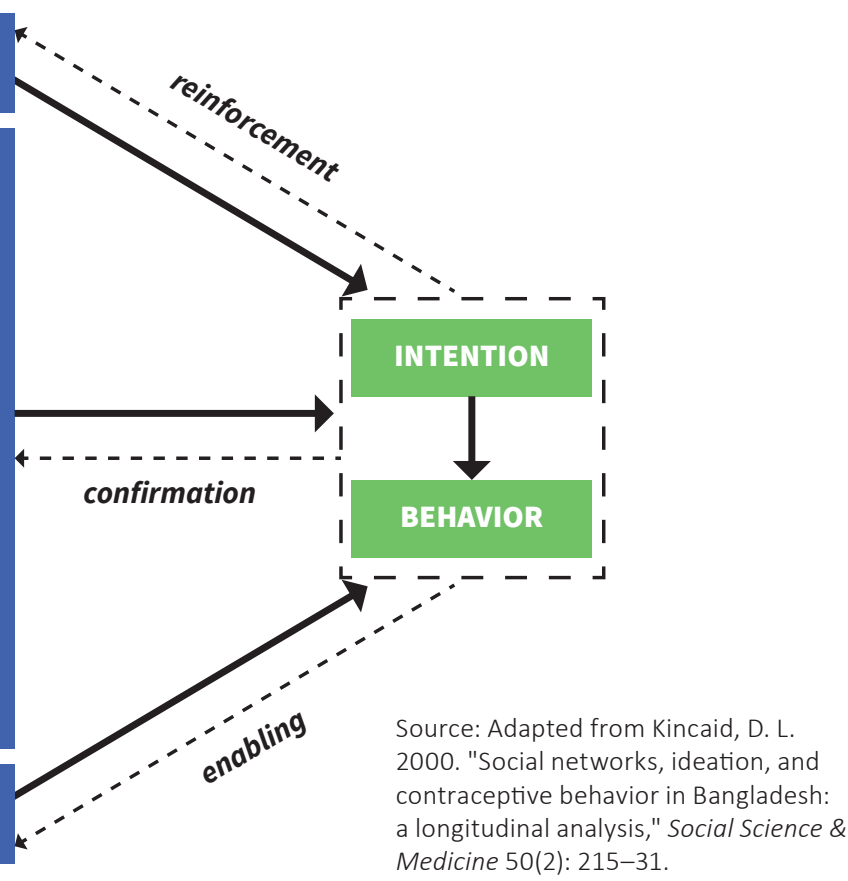


such as the ideational model, which describe stages of the innovation-decision process prior to behavior change.

\section{We propose 12 indicators from the Social and Behavior} Change Indicator Bank for Family Planning and Service Delivery that programs can consider adopting to monitor and evaluate FP SBC programs. While the SBC indicator bank did not include a cost-related indicator, experts recognize the importance of collecting cost-related data to support advocating for SBC investments. ${ }^{3}$ The indicators were selected to align with the ideational model extensively applied by SBC practitioners, which describes stages of the innovationdecision process prior to behavior change. Measures in this process include knowledge, attitudes, emotional determinants such as self-efficacy, and social dimensions such as discussion of FP with one's spouse and friends. Prior to adopting the proposed 12 indicators, program implementers can review formative research to select the ideational components most relevant to the country and programmatic context.

\section{Twelve Indicators to Monitor and Evaluate FP SBC Programs}

The stages that follow (in bold) are detailed in this brief's figure of the ideational model of SBC interventions and are associated with the twelve indicators we propose to monitor and evaluate SBC programs. Cost, though not included in the figure, is also noted here. Twelve Recommended SBC Indicators for Family Planning: Indicator Reference Sheets are available to define the proposed indicator and ensure data quality and consistency (blue text is linked to applicable reference sheet).

Exposure to SBC programming enables us to understand the extent to which beneficiaries are exposed to SBC approaches.

Indicator 1: Number of decision-makers reached with SBC FP advocacy activities.

Indicator 2: Percent of target audience that recalls hearing or seeing a FP message, campaign, or communication initiative.

Indicator 3: Number of service providers trained in interpersonal communication for FP counseling.

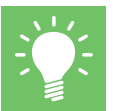

Intermediate enables us to understand the factors contributing to behavioral outcomes.

Indicator 4: Percent of target audience that knows of at least three modern FP methods.

Indicator 5: Percent of target audience with favorable attitudes of modern FP methods.
Indicator 6: Percent of target audience that believes most people in their community approve of people like them using FP.

Indicator 7: Percent of target audience confident in its ability to use FP.

Indicator 8: Percent of target audience that discussed FP with spouse or partner.

Intention \& behavioral outcomes enables us to determine if behavior has changed.

Indicator 9: Percent of non-users intending to adopt a modern FP method in the future.

Indicator 10: Percent of target audience currently using a modern FP method.

Indicator 11: Percent of modern FP users intending modern FP method continuation.

Cost.

Indicator 12: Cost per person reached by SBC activities.

\section{References}

${ }^{1}$ Rosen, James E. et al. 2019. The Business Case for Investing in Social and Behavior Change for Family Planning. Breakthrough RESEARCH. Washington DC: Population Council.

2Breakthrough RESEARCH. 2019. "The added value of costing social and behavior change interventions," Research to Practice Brief. Washington, DC: Population Council.

\section{Acknowledgments}

We acknowledge Paul C. Hewett of the Population Council for his technical guidance and review; Nancy Matuszak and Sherry Hutchinson, who provided editorial and design support; and Hope Hempstone, Lindsay Swisher, and Joan Kraft with the United States Agency for International Development, who provided valuable feedback during the development of this brief.

\section{Breakthrough RESEARCH}

Breakthrough RESEARCH catalyzes SBC by conducting state-of-the-art research and evaluation and promoting evidence-based solutions to improve health and development programs around the world.

Breakthrough RESEARCH is made possible by the generous support of the American people through the USAID under the terms of cooperative agreement no. AIDOAA-A-17-00018. The contents of this document are the sole responsibility of the Breakthrough RESEARCH and Population Council and do not necessarily reflect the views of USAID or the United States Government.

Population Council

4301 Connecticut Avenue, NW | Suite 280 | Washington, DC 20008

Tel: +1 2022379400 | breakthroughresearch@popcouncil.org

breakthroughactionandresearch.org

Suggested citation: Breakthrough RESEARCH. 2020. "Twelve recommended SBC indicators for family planning," Breakthrough RESEARCH Programmatic Research Brief. Washington DC: Population Council. 